\title{
CONF-961202--110
}

\section{Void Morphology in Polyethylene/Carbon Black Composites}

\author{
D.W.M. Marr \\ Chemical Engineering and Petroleum Refining Department \\ Colorado School of Mines, Golden, CO 80401
}

M. Wartenberg, K.B. Schwartz.

Raychem Corporation, Menlo Park, CA 94025

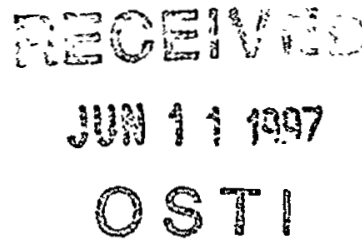

M.M. Agamalian and G.D. Wignall

Solid State Division, Oak Ridge National Laboratories, Oak Ridge, TN 37830

Abstract

A combination of small angle neutron scattering (SANS) and contrast matching techniques is used to determine the size and quantity of voids incorporated during fabrication of polyethylene/carbon black composites. The anailysis used to extract void morphology from SANS data is based on the three-phase model of microcrack determination via small angle $x-$ ray scattering (SAXS) developed by $\mathrm{W} . \mathrm{Wu}^{12}$ and applied to particulate reinforced composites.

\section{Introduction}

Previous SANS and SAXS experiments ${ }^{1}$ have suggested the presence of a third phase (voids) in composites of polyethylene (PE) and carbon black (CB). In this paper, we focus on a set of experiments designed to quantitatively determine the volume fraction and dimensions of voids incorporated during such composite preparation. Analysis of these systems via small angle $x-$ ray scattering techniques is difficult because of their three-phase nature, being composed of polymer matrix, filler, and any incorporated voids. Through a combination of SANS on deuterated and protonated composites, however, the scattering contrast can be varied to reflect either a two or three phase morphology and the size and quantity of voids determined.

$X$-rays are scattered by fluctuations in electron density (ED) within a given sample, and thus carbon black/polyethylene composites have substantial SAXS cross sections due to the large ED difference between the components. The problem however, is that there is strong EDcontrast between carbon black, polyethylene, and voids, making interpretation of scattering data more complex. SANS uses neutrons of wavelength (5-10A) comparable to SAXS and therefore probes similar length scales. Neutrons, however, are scattered by nuclei (as opposed to electrons), and thus the SANS contrast can be changed via isotopic substitution, which has little effect on the chemistry of the blend $d^{2,3}$.

\begin{tabular}{|l|l|l|l|l|}
\hline & $\mathrm{d}\left[\mathrm{g} / \mathrm{cm}^{3}\right]$ & amorph. $\left[10^{10} \mathrm{~cm}^{-2}\right]$ & cryst. $\left[10^{10} \mathrm{~cm}^{-2}\right]$ & ave $\left[10^{10} \mathrm{~cm}^{-2}\right]$ \\
\hline \hline $\mathrm{hPE}$ & $0.953 \pm .001$ & $-0.30\left(\rho_{h P E}^{a}\right)$ & $-0.36\left(\rho_{h P E}^{x}\right)$ & $-0.34\left(\rho_{h P E}^{t}\right)$ \\
\hline $\mathrm{dPE}$ & $1.080 \pm .002$ & $7.30\left(\rho_{d P E}^{a}\right)$ & $8.58\left(\rho_{d P E}^{x}\right)$ & $8.13\left(\rho_{d P E}^{t}\right)$ \\
\hline $\mathrm{CB}$ & $1.917 \pm .002$ & & & $6.40\left(\rho_{C B}\right)$ \\
\hline voids & & & & 0.0 \\
\hline
\end{tabular}

Table 1: Scattering Length Densities

If one examines a normal protonated composite via SANS, the sample is essentially two-phase because the scattering length densities of polyethylene and voids are virtually identical (see Table 1). If one blends carbon black with deuterated polyethylene however, the presence of voids is highlighted within the carbon black/deuterated polyethylene matrix. Through a combination of these two experiments, one can now extract quantitative information about void size and quantity.

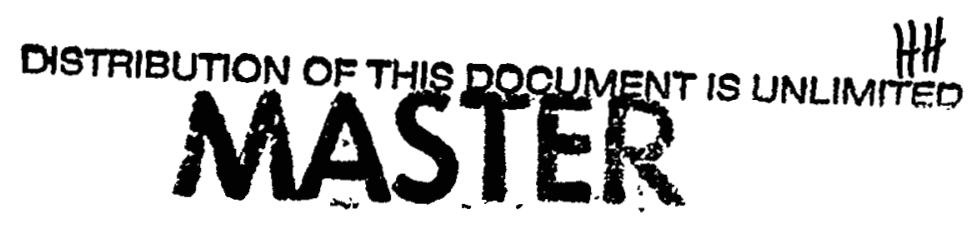

"The submitted manuscript has been authored by a contractor of the U.S. Govemment under contract No. DE-AC0S-960R22464.

Accordingly, the U.S. Govemment retains a non-exclusive, royalty-free license to publish or reproduce the published form of the

contribution, or allow others to do so, for U.S. Government purposes." 


\section{Experiment}

Four composites were prepared at carbon black volume fractions of 0.360 and 0.429 . Two different polymer matrices were used, protonated polyethylene at a density of $0.953 \pm .001$ $\mathrm{g} / \mathrm{cm}^{3}$ and an analogous fully deuterated polyethylene at a density of $1.080 \pm .001 \mathrm{~g} / \mathrm{cm}^{3}$. Composite samples were mixed in a DACA minicompounder ${ }^{4}$, a small scale twin-screw mixer/extruder (for compounding and extrusion of samples up to total volumes of approximately $5 \mathrm{~cm}^{3}$ ). Carbon black and deuterated polyethylene were added in the appropriate ratios to a total weight of $1.5 \mathrm{~g}$ and processed at a temperature of $200^{\circ} \mathrm{C}$ for 5 minutes in the twin screw extruder.

The experiments were performed on the W. C. Koehler 30m SANS facility at Oak Ridge National Laboratory ${ }^{5}$. The neutron wavelength was $4.75 \AA(\Delta \lambda / \lambda \sim 5 \%)$ and the source $(3.5 \mathrm{~cm}$ diameter) and sample (1.0 cm diameter) slits (irises) were separated by a distance of $7.5 \mathrm{~m}$. The sample-detector distances were $4.0 \mathrm{~m}$ and $17.8 \mathrm{~m}$ and the data were corrected for instrumental backgrounds and detector efficiency on a cell-by-cell basis, prior to radial averaging to give a $q$-range of $0.04<q=4 \pi \lambda^{-1} \sin \theta<1.5 \mathrm{~nm}^{-1}$, where $2 \theta$ is the angle of scatter. The net intensities were converted to an absolute $( \pm 4 \%$ differential cross section $[\mathrm{d} \Sigma / \mathrm{d} \Omega(q)]$ per unit sample volume (in units of $\mathrm{cm}^{-1}$ ) by comparison with pre-calibrated secondary standards, based on the measurement of beam flux, vanadium incoherent cross section, the scattering from water and other reference materials ${ }^{6}$. Procedures for transmission measurements and for subtracting the incoherent background, arising largely from the protons in the sample, have been described previously?

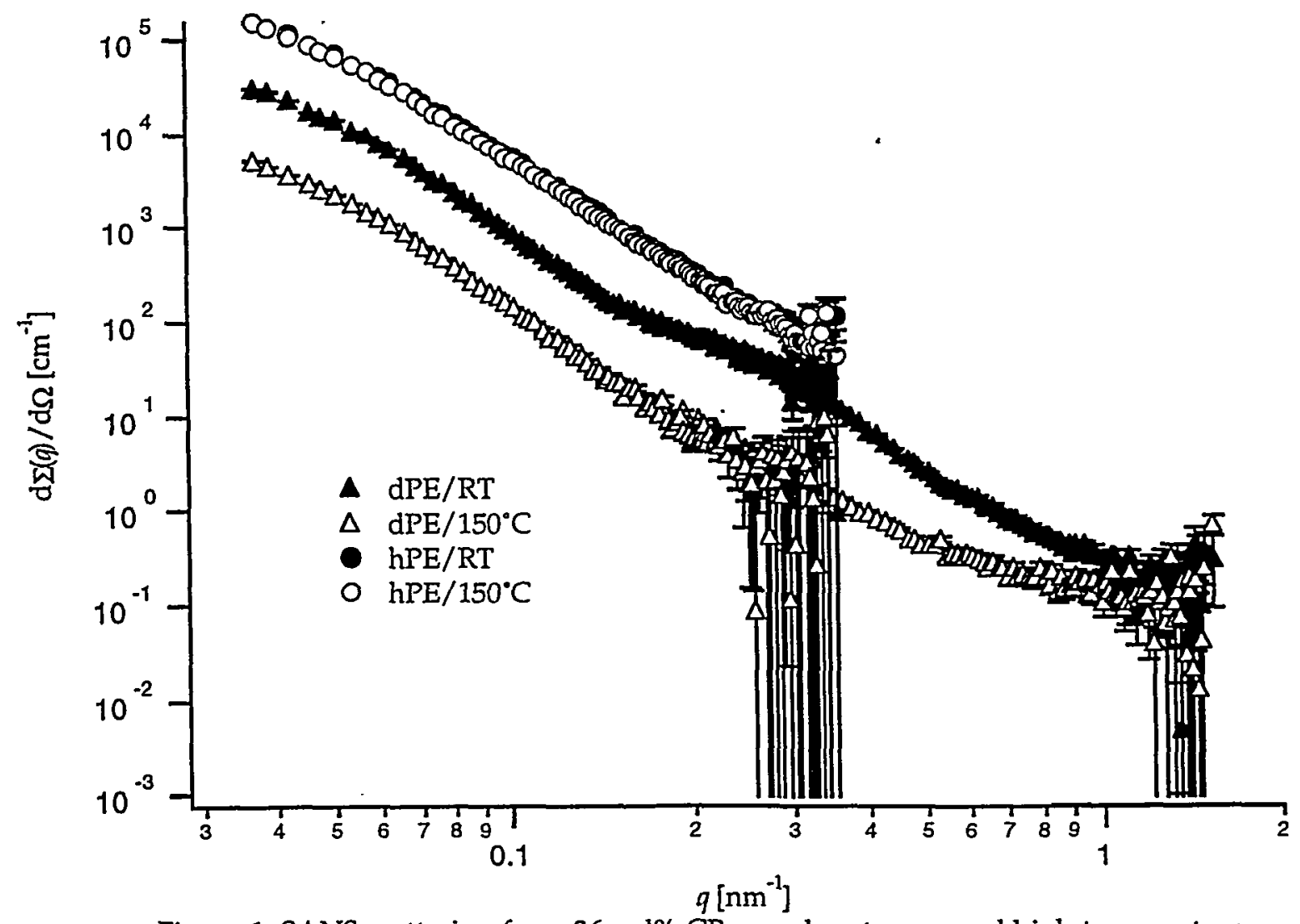

Figure 1: SANS scattering from 36 vol\% CB samples at room and high temperatures 


\section{DISCLAIMER}

This report was prepared as an account of work sponsored by an agency of the United States Government. Neither the United States Government nor any agency thereof, nor any of their employees, make any warranty, express or implied, or assumes any legal liability or responsibility for the accuracy, completeness, or usefulness of any information, apparatus, product, or process disclosed, or represents that its use would not infringe privately owned rights. Reference herein to any specific commercial product, process, or service by trade name, trademark, manufacturer, or otherwise does not necessarily constitute or imply its endorsement, recommendation, or favoring by the United States Government or any agency thereof. The views and opinions of authors expressed herein do not necessarily state or reflect those of the United States Government or any agency thereof. 


\section{DISCLAMIER}

Portions of this document may be illegible in electronic image products. Images are produced from the best available original document. 
Analysis

Figure 1 shows the SANS differential cross section $d \Sigma / d \Omega(q)$ for two composite samples with a carbon black volume fraction of $36.0 \%$. It may be seen that substituting dPE for hPE lowers the scattered intensity as expected. In addition, due to the difference in SLD between crystalline and amorphous regions in deuterated polyethylene (see Table 1) there is a "peak" associated with lamellar spacing in crystalline polyethylene around $q=.25 \mathrm{~nm}^{-1}$ in the room temperature data for deuterated composites. Also of note is that the cross sections of the protonated samples at room temperature and in the melt are very similar. The SANS contrast in this system is developed primarily from the difference in scattering length density between $\mathrm{hPE}$ and carbon black, neither of which change significantly with an increase in temperature.

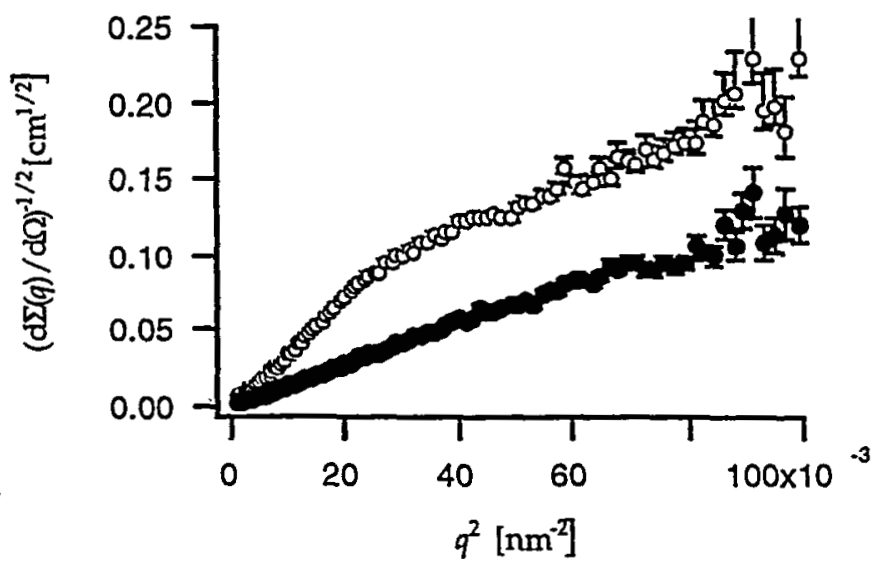

Figure 2: Debye-Bueche plot of a deuterated $\left(^{\circ}\right)$ and protonated $(\bullet)$ composite showing the linear behavior of the protonated sample.

This "two-phase" behavior of the protonated composites is clearly shown in the Debye-Bueche (DB) plot of Figure 2. The linear slope suggests that a single-parameter DB analysis is appropriate in this system and shows that we must use a more complex model for analysis of the deuterated systems. Interpreting the data for the protonated composites in the DB model ${ }^{8}$ with

$\gamma(r)=e^{-r / a_{c}}$ and $\frac{d \Sigma(q)}{d \Omega}=\frac{d \Sigma(0)}{d \Omega}\left(1+q^{2} a_{c}^{2}\right)^{-2}$,

chord lengths (or domain sizes) of the individual phases can be determined via $l_{i}=\frac{1}{1-\phi_{i}} \int_{0}^{\infty} \gamma(r) d r$ or $l_{1}=\frac{a_{c}}{1-\phi_{1}}$ and $l_{2}=\frac{a_{c}}{\phi_{1}}$.

\begin{tabular}{|l|l|l|l|l|l|l|l|l|}
\hline matrix & Temp & $\phi_{\mathrm{CB}}$ & $\begin{array}{l}\mathrm{d} \Sigma / \mathrm{d} \Omega(0) \\
{\left[\mathrm{cm}^{-1}\right]}\end{array}$ & $\begin{array}{l}a_{\mathrm{c}} \\
{[\mathrm{nm}]}\end{array}$ & $\begin{array}{l}Q^{\operatorname{cp}} \times 10^{-22} \\
{\left[\mathrm{~cm}^{-4}\right]}\end{array}$ & $\begin{array}{l}Q^{\text {pred }} \times 10^{-22} \\
{\left[\mathrm{~cm}^{-1}\right]}\end{array}$ & $\begin{array}{l}l_{2} \\
{[\mathrm{~nm}]}\end{array}$ & $\begin{array}{l}l_{2} \\
{[\mathrm{~nm}]}\end{array}$ \\
\hline \hline $\mathrm{hPE}$ & $\mathrm{RT}$ & 0.360 & $1.72 \pm .02 \times 10^{6}$ & $40.7 \pm .1$ & $2.00 \pm .04$ & 2.06 & $63.6 \pm .2$ & $113.1 \pm .3$ \\
\hline $\mathrm{hPE}$ & $150^{\circ} \mathrm{C}$ & 0.335 & $2.14 \pm .03 \times 10^{6}$ & $43.7 \pm .1$ & $2.01 \pm .04$ & 1.97 & $65.7 \pm .2$ & $130.4 \pm .3$ \\
\hline $\mathrm{hPE}$ & $\mathrm{RT}$ & 0.429 & $1.43 \pm .01 \times 10^{6}$ & $36.4 \pm .1$ & $2.34 \pm .03$ & 2.19 & $63.7 \pm .2$ & $84.8 \pm .3$ \\
\hline $\mathrm{hPE}$ & $150^{\circ} \mathrm{C}$ & 0.402 & $1.67 \pm .02 \times 10^{6}$ & $38.5 \pm .1$ & $2.29 \pm .05$ & 2.13 & $64.4 \pm .2$ & $95.9 \pm .3$ \\
\hline
\end{tabular}

Table 2: Fit parameters (the volume fractions have changed at high temperature because of the expansion of the PE phase).

The scattering invariant $Q$

$Q=\int_{0}^{\infty} q^{2} \frac{d \Sigma(q)}{d \Omega} d q$ can be used to verify our choice of model because $Q=2 \pi^{2} \phi_{1} \phi_{2}\left(\rho_{1}-\rho_{2}\right)^{2}$ for two-phase systems. To account for the lack of data at low and high $q$, experimental invariants were generated by integrating the model fits to the data. Our results for these fits are shown in Table 2. The domain size $l_{1}$ corresponds to the phase at volume fraction $\phi_{1}$ (carbon black) as confirmed by the fact that it does not vary as the sample is brought through the melt transition. Note also the domain size of the polyethylene phase behaves as expected. As the samples are melted the domain size increases, indicating the polyethylene expansion; also, the domain size decreases as the polymer volume fraction is lowered. With a knowledge of the SLDs and volume fractions of the components we have generated predicted invariants for comparison to those determined experimentally. As seen in Table 2 the agreement is quite good at lower concentration, indicating that we have a good handle on the analysis for protonated polyethylene/carbon black composites and that this system effectively behaves as two-phases. 
To obtain experimental values for $Q$ at higher concentrations, the data were fit to the twocorrelation length Debye-Bueche model ${ }^{9,10, \mathrm{R}}$,

$$
\frac{d \Sigma(q)}{d \Omega}=\frac{A_{1}}{\left(1+q^{2} a_{1}^{2}\right)^{2}}+A_{2} \exp \left(-\frac{q^{2} a_{2}^{2}}{4}\right) \text { where } \frac{d \Sigma(0)}{d \Omega}=A_{1}+A_{2} \text { and } f=\frac{A_{1}}{A_{1}+\frac{8 A_{2}}{\sqrt{\pi}}\left(\frac{a_{1}}{a_{2}}\right)^{3}} \text {, and improving }
$$

the agreement between the predicted and experimental invariants to within $2 \%$.

In examining the deuterated composites, we have seen in Figure 2 that they are not well described by the single-parameter Debye-Bueche model. For two-phase systems, and as seen in the protonated composite case, this model should fit well. Such a deviation indicates that something else is present in these systems that has no SANS contrast in the protonated polyethylene but shows up in the deuterated polymer case at low $q$, i.e. voids ${ }^{1}$. This inference is supported by the difference in the calculated and predicted scattering invariants shown in Table 3. Notice that in each of the cases, the experimental invariant is higher than one would predict for a simple two-phase system, indicating once ágain that there is another phase at low $q$ contributing to the total scattering.

\begin{tabular}{|l|l|l|l|l|l|l|l|l|l|}
\hline & Temp & $\phi_{\mathrm{CB}}$ & $\begin{array}{l}a_{1} \\
{[\mathrm{~nm}]}\end{array}$ & $\begin{array}{l}a_{2} \\
{[\mathrm{~mm}]}\end{array}$ & $\begin{array}{l}\mathrm{A}_{1} \times 10^{-4} \\
{\left[\mathrm{~cm}^{-1}\right]}\end{array}$ & $\begin{array}{l}\mathrm{A}_{2} \times 10^{-3} \\
{\left[\mathrm{~cm}^{-1}\right]}\end{array}$ & $\begin{array}{l}Q^{\text {ap }} \times 10^{-20} \\
{\left[\mathrm{~cm}^{-4}\right]}\end{array}$ & $\begin{array}{l}Q^{\text {pred }} \times 10^{-20} \\
{\left[\mathrm{~cm}^{-4}\right]}\end{array}$ \\
\hline \hline $\mathrm{dPE}$ & $\mathrm{RT}$ & 0.360 & $40.3 \pm .1$ & $45.9 \pm .3$ & $22.9 \pm 1.4$ & $17.5 \pm .6$ & 0.811 & $33.9 \pm 3.4$ & 13.1 \\
\hline $\mathrm{dPE}$ & $150^{\circ} \mathrm{C}$ & 0.336 & $38.7 \pm .1$ & $44.9 \pm .1$ & $3.20 \pm .33$ & $2.58 \pm .15$ & 0.812 & $5.36 \pm .95$ & 3.57 \\
\hline $\mathrm{dPE}$ & $\mathrm{RT}$ & 0.429 & $37.0 \pm .1$ & $43.8 \pm .3$ & $19.0 \pm .9$ & $17.3 \pm .5$ & 0.801 & $36.8 \pm 2.9$ & 14.0 \\
\hline $\mathrm{dPE}$ & $150^{\circ} \mathrm{C}$ & 0.403 & $36.0 \pm .1$ & $41.1 \pm .3$ & $2.91 \pm .23$ & $2.82 \pm .12$ & 0.796 & $6.16 \pm .83$ & 3.85 \\
\hline
\end{tabular}

Table 3: Results from 2-parameter DB model fits (to avoid the complications added by the crystalline lamellae in dPE, the data here were fit over a range of $0.037 \mathrm{~nm}^{-1}<q<0.126 \mathrm{~nm}^{-1}$, corresponding to length scales greater than $50 \mathrm{~nm}$ ).

Assuming that the structure of the three-component composite (polyethylene, carbon black, and voids) is identical in the deuterated and protonated cases, one can extract quantitative

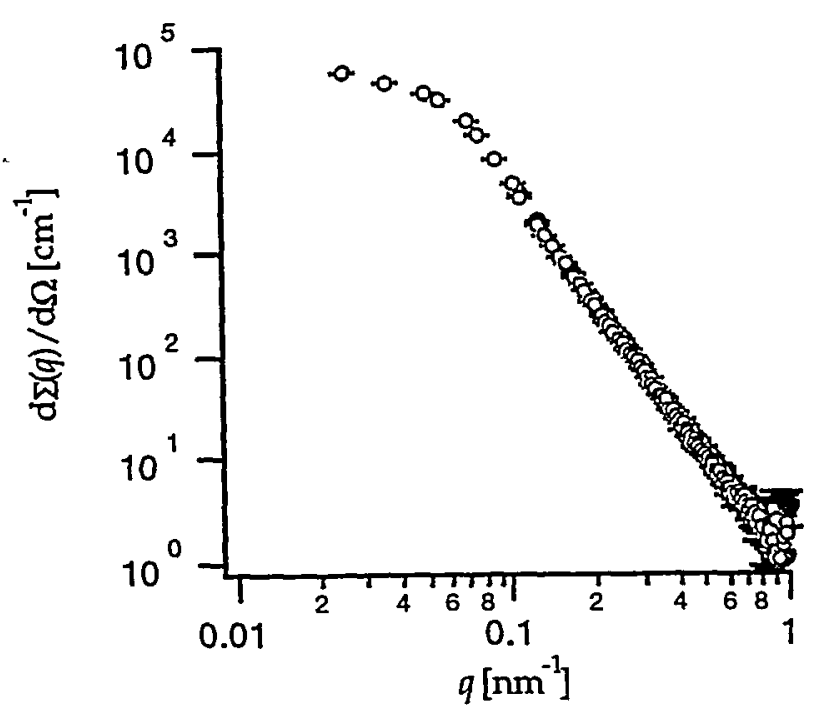

Figure 3: SAXS scattering from 36 vol\% carbon black samples where the scattering from both deuterated $\left(^{\circ}\right)$ and protonated $(\bullet)$ composites overlap. information about void size and quantity. SAXS can be used to validate this hypothesis because of the sensitivity of $x-$ rays to the scattering contrast between both polyethylenes (hPE/dPE) as well as carbon black. As displayed in Figure 3, the SAXS scattering patterns from the deuterated and protonated polyethylene composites overlap showing the microstructures to be virtually identical over the length scales investigated. Thus, it is reasonable to use the scattering data from the protonated samples as a template for the expected SANS scattering curves of the deuterated materials if composed of only two phases. We then attribute the excess scattering to the third phase.

composite materials. By comparing the SAXS scattering from undamaged composites to damaged composites he could extract the size and quantity of the void phase. This approach is analogous to our comparisons of systems that are effectively two phase with those of similar 
morphology but with the addition of a small void component (deuterated composites). One begins by expressing the correlation function for the entire system as a summation of the correlations for the individual phases $\gamma_{1}(\mathbf{r})$ as if the other phases composed a single phase: $\gamma(\mathbf{r}) \propto \phi_{1}\left(1-\phi_{1}\right)\left(\rho_{2}-\rho_{1}\right)\left(\rho_{3}-\rho_{1}\right) \gamma_{1}(\mathbf{r})+\phi_{2}\left(1-\phi_{2}\right)\left(\rho_{3}-\rho_{2}\right)\left(\rho_{1}-\rho_{2}\right) \gamma_{2}(\mathbf{r})+\phi_{3}\left(1-\phi_{3}\right)\left(\rho_{1}-\rho_{3}\right)\left(\rho_{2}-\rho_{3}\right) \gamma_{3}(\mathbf{r})$ For three-phase isotropic systems (phase $1=$ filler, phase $2=$ matrix, phase $3=$ voids) the invariant can then be determined via

$$
Q=\int_{0}^{\infty} q^{2} \frac{d \Sigma(q)}{d \Omega} d q=2 \pi^{2}\left[\phi_{1} \phi_{2}\left(\rho_{1}-\rho_{2}\right)^{2}+\phi_{2} \phi_{3}\left(\rho_{2}-\rho_{3}\right)^{2}+\phi_{1} \phi_{3}\left(\rho_{1}-\rho_{3}\right)^{2}\right]
$$

If we denote $Q^{0}$ as the invariant for a system without voids then

$$
\begin{gathered}
Q^{0}=2 \pi^{2} \phi_{1}^{0}\left(1-\phi_{1}^{0}\right)\left(\rho_{1}-\rho_{2}^{0}\right)^{2} \text { and } \\
Q-Q^{0}\left(\frac{\rho_{1}-\rho_{2}}{\rho_{1}-\rho_{2}^{0}}\right)^{2}=2 \pi^{2}\left[\left(\rho_{1}-\rho_{2}\right)^{2}\left(\phi_{1}\left(1-\phi_{1}\right)-\phi_{1}^{0}\left(1-\phi_{1}^{0}\right)-\phi_{1} \phi_{3}\right)+\phi_{2} \phi_{3}\left(\rho_{2}-\rho_{3}\right)^{2}+\phi_{1} \phi_{3}\left(\rho_{1}-\rho_{3}\right)^{2}\right] .
\end{gathered}
$$

If one examines isothermal transitions from deuterated to protonated composites, the filler correlations and volume fractions will not vary (i.e. $\gamma_{1}(r)=\gamma_{1}^{0}(r), \phi_{1}=\phi_{1}^{0}$ ) and the volume fraction of the void phase can be calculated via

$$
\phi_{3}=\frac{Q-Q^{0}\left(\frac{\rho_{1}-\rho_{2}}{\rho_{1}-\rho_{2}^{0}}\right)^{2}}{2 \pi^{2}\left\{\phi_{1}\left[\left(\rho_{1}-\rho_{3}\right)^{2}-\left(\rho_{1}-\rho_{2}\right)^{2}-\left(\rho_{2}-\rho_{3}\right)^{2}\right]+\left(1-\phi_{3}\right)\left(\rho_{2}-\rho_{3}\right)^{2}\right\}} .
$$

In addition, one can calculate the chord length of this low volume fraction domain in a similar fashion. For three-phase systems

$$
Z=\int_{0}^{\infty} q \frac{d \Sigma(q)}{d \Omega} d q=4 \pi\left[\begin{array}{l}
\left(\rho_{2}-\rho_{1}\right)\left(\rho_{3}-\rho_{1}\right) \phi_{1}\left(1-\phi_{1}\right) \int_{0}^{\infty} \gamma_{1}(r) d r+ \\
\left(\rho_{3}-\rho_{2}\right)\left(\rho_{1}-\rho_{2}\right) \phi_{2}\left(1-\phi_{2}\right) \int_{0}^{\infty} \gamma_{2}(r) d r+\left(\rho_{1}-\rho_{3}\right)\left(\rho_{2}-\rho_{3}\right) \phi_{3}\left(1-\phi_{3}\right) \int_{0}^{\infty} \gamma_{3}(r) d r
\end{array}\right] .
$$

Assuming the volume fraction of voids is small and that the chord lengths of phases 1 and 2 remain constant, the chord length of the void domain can be estimated via

$$
l_{3}=\frac{Z-Z^{0}\left(\frac{\rho_{1}-\rho_{2}}{\rho_{1}-\rho_{2}^{0}}\right)^{2}}{4 \pi \phi_{3}\left(1-\phi_{3}\right)\left(\rho_{1}-\rho_{3}\right)\left(\rho_{2}-\rho_{3}\right)} .
$$

\section{Results and Discussion}

These investigations include four experiments where the composite has gone from two to three phases under conditions of constant filler volume fraction. Using the equations developed in the previous section we can now determine the void volume fractions and associated chord lengths, the results of which are shown in Table 4 . For the room temperature composites, we find a void size of $44 \pm 24 \mathrm{~nm}$ and a void content of $1.9 \pm 0.3$ vol\% for the 36.0 vol\% sample. For the 42.9 vol\% sample we obtain values of $42 \pm 18 \mathrm{~nm}$ and $2.1 \pm 0.3 \mathrm{vol} \%$. Once the composites are heated above the melting point, there is a significant decrease in the void content, to a value of the same order as the experimental error. This decrease might be expected and suggests that the polyethylene domains grow at the expense of the voids as the temperature is brought above the melt. Also of note, and despite the limited data, is the apparent scaling of the void content with filler concentration both at room and high temperatures. 


\begin{tabular}{|l|l|l|l|l|l|}
\hline Temp & $\phi_{1}(\mathrm{CB})$ & $\phi_{3}$ (voids) & $h_{1}[\mathrm{~nm}](\mathrm{CB})$ & $h_{2}[\mathrm{~nm}](\mathrm{PE})$ & $\zeta_{3}[\mathrm{~nm}]$ (voids) \\
\hline \hline $\mathrm{RT}$ & 0.360 & $0.0188 \pm .0033$ & $61.7 \pm 1.0$ & $109.7 \pm 1.8$ & $44.0 \pm 24.0$ \\
\hline $150^{\circ} \mathrm{C}$ & 0.335 & $0.0018 \pm .0011$ & $67.1 \pm 1.2$ & $133.1 \pm 2.5$ & $29.7 \pm 152$ \\
\hline $\mathrm{RT}$ & 0.429 & $0.0212 \pm .0032$ & $57.9 \pm 1.9$ & $77.0 \pm 2.6$ & $42.0 \pm 18.0$ \\
\hline $150^{\circ} \mathrm{C}$ & 0.402 & $0.0025 \pm .0010$ & $57.0 \pm 1.9$ & $84.7 \pm 2.8$ & $40.0 \pm 74.4$ \\
\hline
\end{tabular}

Table 4: Results

Though we currently do not have a technique that would allow us to corroborate our void size determinations, we have conducted a number of pycnometry measurements at room temperature on similarly prepared materials in order to compare to the void volume results. The void content was determined by comparing the measured densities with those predicted assuming a lack of voids via void content $=\left(1-\rho_{\text {meas }}\right) / \rho_{\text {pred }}$ (see Figure 4 ). Despite the small range over which these pycnometry experiments were conducted, the results indicate that the void contents determined via the scattering studies are quite reasonable.

These results do not allow us to determine the mechanism of void incorporation but do provide some interesting clues. We have seen in these investigations that the void volume fraction decreases to near zero above the melt. This strongly suggests that the system is nearly completely wetted during processing and that most of the void incorporation occurs post processing during composite cool. We have also seen however, that the void content scales with filler concentration, suggesting that entrainment may be involved and that carbon black structure will play a significant role in void quantity and

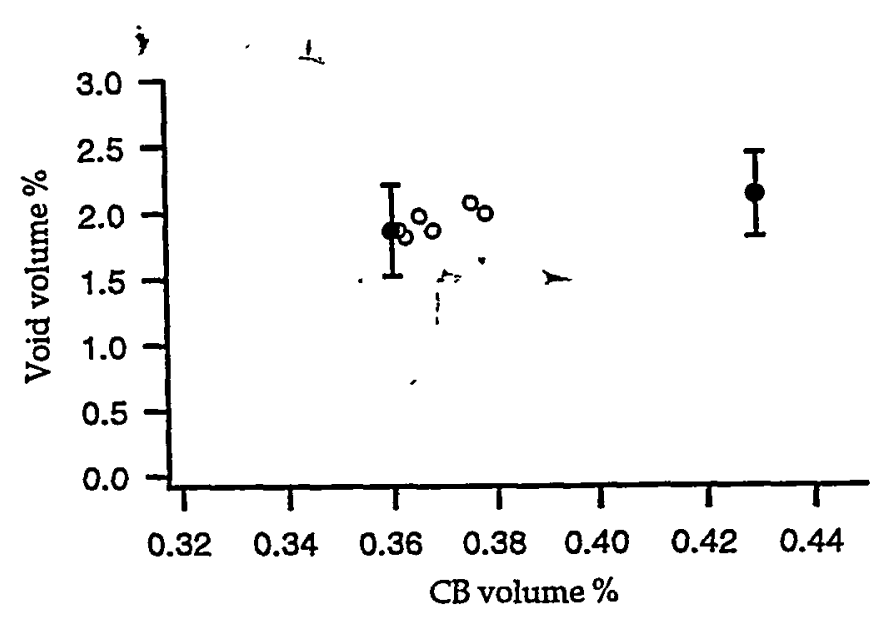

Figure 4: Void content determined via SANS $(\bullet)$ and pycnometry $\left({ }^{\circ}\right)$ at room temperature.

morphology. This apparent contradiction will serve as motivation for future studies into the influence of these factors on the system morphology.

\section{Acknowledgments}

We thank Gordon Spellman at Lawrence Livermore National Laboratories for supplying the deuterated polyethylene used in this study. The research at Oak Ridge was supported by the Division of Materials Sciences, U. S. Department of Energy under contract No. DE-AC0596OR22464 with Lockheed Martin Energy Research Corporation.

\section{References}

${ }^{1}$ Wignall, G.D.; Farrar, N.R.; Morris, S. J. Mat. Sci. 1990, 25, 69.

${ }^{2}$ Bates, F. S.; Wignall, G. D. Phys. Rev. Lett., 1986, 57, 1429.

${ }^{3}$ Wignall, G. D. Polymer Properties Handbook, American Institute of Physics, 1996, 299.

${ }^{4}$ DACA Instruments, Santa Barbara, CA.

${ }^{5}$ Koehler, W. C. Physica (Utrecht), 1986, 137B, 320.

${ }^{6}$ Bates, F. S.; Wignall, G. D. J. Appl. Cryst., 1986, 20, 28.

7 Dubner, W. S.; Schultz, J. M.; Wignall, G. D. J. Appl. Cryst., 1990, 23, 469.

${ }^{8}$ Debye, P.; Bueche, A.M. J. Appl. Phys. 1949, 20, 518.

9 Debye, P.; Anderson, H.R.; Brumberger, H. J. Appl. Phys. 1957, $28,679$.

${ }^{10}$ Cheung, Y.W:, Stein, R.S., Wignall, G.D, Yang, H.E. Macromolecules 1993, 26, 5365.

${ }^{11}$ Marr, D.W.M. Macromolecules 1995, 28, 8470.

${ }^{12}$ Wu, W.-L Polymer 1982, 23, 1907. 